\title{
Murcha-de-Phytomonas, uma Nova Doença do Coqueiro em Mato Grosso
}

\author{
Napoleão Silvino de Souza \\ Empresa Mato-grossense de Pesquisa, Assistência e Extensão Rural - EMPAER- MT, Rua do Pintado s/n, Bairro Ponte \\ Nova, CEP 78115-100, Várzea Grande, MT, Fax: (65) 648-9285, e-mail: napo.souza@ bol.com.br
}

(Aceito para publicação em 12/01/2005)

Autor para correspondência: Napoleão Silvino de Souza

\begin{abstract}
Phytomonas wilt, a new coconut disease in the State of Mato Grosso

A severe attack of Phytomonas staheli was observed in samples of coconut (Cocos nucifera) originating in plantations of Terra Nova do Norte, Mato Grosso in August 2002. This is the first report of P. staheli causing wilt in coconut in Mato Grosso.
\end{abstract}

A cultura do coqueiro (Cocos nucifera L.) no Estado de Mato Grosso tem tido um incremento significativo na área de plantio, com 3.671 ha em 2002/2003 (Fonte: IBGE, 2003) atendendo a crescente demanda do consumo interno. Em agosto de 2002, foi registrada a ocorrência de uma nova doença nesta cultura na região de Terra Nova do Norte, MT (Figura 1). A enfermidade caracteriza-se por murcha das folhas inferiores, que progride para cima rodeando o estipe, sem afetar as folhas do topo. As folhas adquirem coloração marrom-escura que progride do ápice para a base e se dobram no encontro do estipe ficando penduradas por algum tempo. As inflorescências não abertas apresentam necrose que se inicia nas extremidades dos ráquis florais e adquirem coloração castanha.

Em cortes realizados no sentido longitudinal e transversal da ponta do estipe, foram observadas necrose de coloração marrom-avermelhada (castanha) e podridão fétida do broto apical, causando destruição do palmito e morte da folha flecha. Exames microscópicos de gota de seiva extraída de amostra de tecido do caule mostraram que o patógeno apresentava as seguintes características morfológicas: protozoários fusóides e filiformes, afinados posteriormente e terminando na parte anterior por um flagelo. Foi constatada, também, a motilidade dos organismos. Assim, ficou confirmado tratar-se de doença causada por Phytomonas staheli (McGhee \& McGhee) conforme descrito por Bezerra $\&$ Figueiredo (Fitopatol. Bras. 7:139-143. 1982). Manter as plantas em ambiente limpo, efetuar poda de limpeza para a retirada das folhas mais velhas, bainhas mortas, as quais podem abrigar o percevejo vetor, e eliminar as plantas infetadas constituem alternativas para o controle da doença. Este é o primeiro relato de $P$. staheli causando murcha em coqueiro no Estado de Mato Grosso.

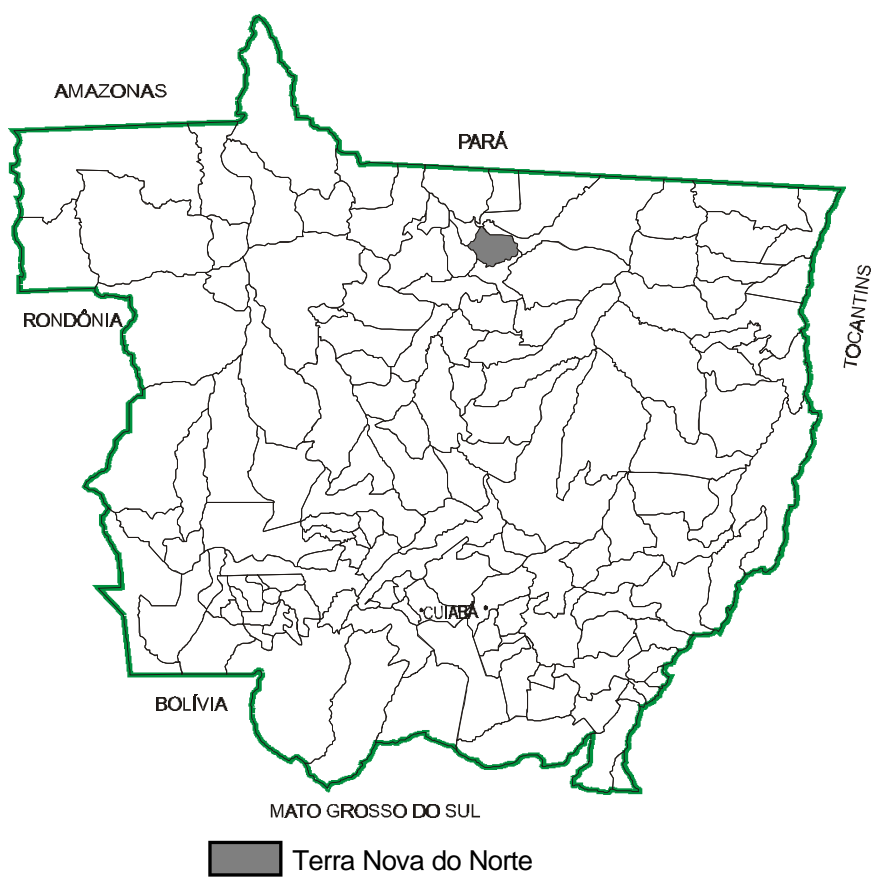

FIG. 1 - Localização do município de Terra Nova do Norte, MT, onde foi registrada a ocorrência de Murcha-de-Phytomonas em coqueiro (Cocos nucifera). 